(C) 2021, The Authors. Published by Elsevier Inc. and Fass Inc. on behalf of the American Dairy Science Association ${ }^{\circledR}$. This is an open access article under the CC BY-NC-ND license (http://creativecommons.org/licenses/by-nc-nd/4.0/).

\title{
Reproductive hormone use and its association with herd-level factors on Dutch dairy farms
}

\author{
J. S. M. van der Laan, ${ }^{1} \oplus$ P. L. A. M. Vos, ${ }^{1}$ B. H. P. van den Borne, ${ }^{2} \odot$ H. Aardema, ${ }^{1} \oplus$ and T. van Werven ${ }^{1,3 *} \odot$ \\ ${ }^{1}$ Department of Farm Animal Health, Faculty of Veterinary Medicine, Utrecht University, $3584 \mathrm{CL}$, Utrecht, the Netherlands \\ 2Business Economics Group, Wageningen University, 6706 KN, Wageningen, the Netherlands \\ ${ }^{3}$ University Farm Animal Practice (ULP), 3481 LZ, Harmelen, the Netherlands
}

\begin{abstract}
We studied the use of the 3 commonly used reproductive hormones, namely prostaglandins, GnRH, and progesterone, and associated herd-level factors on 760 Dutch dairy farms from 5 veterinary clinics. From 2017 to 2019 we collected data on the sales of reproductive hormones, converted this data into the number of reproductive hormone doses conducted, and expressed this as the annual number of reproductive hormone doses per 100 adult dairy cows. Additional herd-level information was available for 2019. Due to the excess of zeros in the data set (i.e., a substantial number of farms did not use any hormones), we used a zeroinflated negative binomial model to identify related herd-level factors for the use of reproductive hormones. In the entire study period of 2017 to $2019,5.8 \%$ of the dairy farms did not use any reproductive hormones, with the proportion of nonusers varying between 0.0 and $10.3 \%$ per veterinary clinic. This proportion was around $13.5 \%$ on an annual basis. Prostaglandins were the most frequently used reproductive hormone in Dutch dairy cows (62.9\%), followed by $\mathrm{GnRH}(33.1 \%)$ and progesterone $(4.0 \%)$. Furthermore, participating in a veterinary herd health management program had a significant effect on reproductive hormone use. These farms used more reproductive hormones than farms that did not participate in a herd health management program and were less represented in the group of nonuser farms. Technologies, such as pedometers and automatic milking systems, also had an effect on reproductive hormone use. The presence of pedometers or activity monitors did not reduce the use of the reproductive hormones but was associated with a greater frequency of users. Farms with an automatic milking system used more reproductive hormones than farms with a conventional milking system. With this study, we have made a first step in achieving transparency
\end{abstract}

Received October 14, 2020.

Accepted June 7, 2021.

*Corresponding author: t.vanwerven@uu.nl in the Dutch dairy industry by providing an objective overview of reproductive hormone use on Dutch dairy farms and identifying associations with some herd-level factors.

Key words: hormone treatment, reproduction, management, dairy cow

\section{INTRODUCTION}

Globally, reproductive hormones are used in the dairy industry to increase reproductive efficiency and, hence, to increase the longevity of dairy cows (Moore and Hasler, 2017; Schuster et al., 2020). The number of treatments seems to vary between herds, but exact numbers of reproductive hormone use are lacking for almost all countries. Variation between countries appears to be highly dependent on a farm's management system, including the type of calving pattern used (i.e., seasonal or year-round). In grassland-based systems, as in New Zealand or Ireland, seasonal calving patterns allow mating only within a restricted time frame during the year to align calving (Lucy et al., 2004; Laven, 2019). In these countries, fixed-time AI protocols are therefore important tools when striving for an efficient dairy production system (McDougall and Compton, 2006; Crowe et al., 2018). These protocols involve multiple hormone doses per cow, varying from 3 to 7 doses per protocol, leading to an intensive use of reproductive hormones (Nowicki et al., 2017; Santos et al., 2017). In the Netherlands, the calving pattern is year-round, and, consequently, treatments tend to be prescribed at the cow level rather than making use of synchronization protocols at the herd level. The majority of reproductive hormone treatments are diagnosis-based treatments given to individual cows using specifically designed and registered reproductive hormone preparations, including, for example, treatments for estrus induction and the treatment of repeat-breeding cows or reproductive diseases, such as ovarian cysts and pyometras (KNMvD, 2013).

In the last decade, the use of pharmaceutical products such as reproductive hormones and antibiotics has 
been scrutinized in animal husbandry, including dairy farming. Consumers' growing interest in food safety and cases of pharmaceutical product misuse have resulted in a skepticism among the general population regarding the use of antimicrobials and hormones in modern farming (Refsdal, 2000; Pieper et al., 2016). Due to the emerging threat of antimicrobial resistance worldwide, European countries, especially the Netherlands, have focused on the reduction of antibiotics by introducing government regulations and monitoring guidelines (e.g., Pugh, 2002; Speksnijder et al., 2015). Consequently, these governmental actions also limit the use of routine prescriptions to mask underlying management shortcomings. Hormones do not play a role in the emergence of resistant bacteria, but consumers have concerns about possible hormone residues in animal products (Refsdal, 2000; Pieper et al., 2016). Food safety is considered one of the most important attributes of public perception in Dutch dairy farming (Van Calker et al., 2005). Although negative effects of reproductive hormones are not described, the Dutch public is concerned about the use of reproductive hormones in modern farming (Boogaard et al., 2011), despite their lack of basic knowledge about the dairy industry (Pieper et al., 2016).

Little quantitative data are available on the use of reproductive hormone treatments on dairy farms. A Canadian study reported that $84 \%$ of the studied farms applied reproductive hormones, and the majority of these farms (58\%) used them to synchronize the timing of ovulation for fixed-time AI (Denis-Robichaud et al., 2016). In the United Kingdom, on the other hand, a questionnaire among veterinary practitioners revealed that $99.4 \%$ of the attending farms used hormones, of which $7.8 \%$ used hormones for fixed-time AI protocols (Higgins et al., 2013). To our knowledge, actual quantitative numbers representing reproductive hormone use have not yet been estimated for a representative sample of herds with a year-round calving pattern. Therefore, the aim of this study is to estimate reproductive hormone use on year-round calving dairy farms under Dutch circumstances and to obtain insight into herd-level factors that are associated with reproductive hormone use.

\section{MATERIALS AND METHODS}

\section{Data Collection}

Data on the sale of reproductive hormones to dairy farms between 2017 and 2019 were obtained through the practice management systems of 5 veterinary clinics in the Netherlands and exported to a digital spreadsheet (MS Excel 365, Microsoft Corp.). The 5 clinics were
Table 1. Description of the 5 veterinary clinics and the 760 dairy herds included in the data set in 2019

\begin{tabular}{lccc}
\hline Clinic ID & $\begin{array}{c}\text { Farms } \\
(\mathrm{n})\end{array}$ & $\begin{array}{c}\text { Cows } \\
(\mathrm{n})\end{array}$ & $\begin{array}{c}\text { Average herd } \\
\text { size (n) }\end{array}$ \\
\hline 1 & 154 & 18,481 & 120 \\
2 & 136 & 18,553 & 136 \\
3 & 91 & 14,616 & 161 \\
4 & 91 & 10,106 & 111 \\
5 & 288 & 25,709 & 89 \\
Total & 760 & 87,465 & 115 \\
\hline
\end{tabular}

selected based on their geographical distribution from the north to the south of the Netherlands, and all were members of Kernpraktijken Rundvee, a cooperative of 15 farm animal veterinary clinics in the Netherlands. All dairy farms belonging to the 5 practices yielded a total of 760 farms with an average annual total across the 3 study years of 88,924 adult dairy cows, representing $4.7 \%$ of the Dutch dairy farm population and $5.5 \%$ of the total number of adult dairy cows in the Netherlands (Central Bureau for Statistics, 2020). Table 1 shows the distribution of the number of farms and cows among the veterinary clinics in 2019 . The veterinary clinics varied regarding their size, with clinic 5 being the largest in terms of the number of both served farms and cows. The total number of adult dairy cows and average herd size decreased in all veterinary clinics in 2019 compared with 2017 and 2018. The decrease in the total number of cows ranged from $-6.3 \%$ to $-1.6 \%$ per veterinary clinic.

Each year the same farms were included in the data set. Two additional farms from veterinary clinic 5 enrolled in the study in 2018 and 2019 and were considered as missing values in previous years. Information on the 760 farms entered into the data set, which included herd-level information on the sales of reproductive hormones and herd size, were reported per quarter of a year. Data on the use of reproductive hormones were based on sales invoices, whereby reproductive hormones per farm were quantified in milliliters per product or per device per quarter of a year from 2017 to 2019. Dairy farms that did not buy any reproductive hormone in one or multiple quarters of a year were also included in the study. Farms with unknown herd sizes were excluded from the analysis, to allow standardization of herd size. The 5 veterinary clinics were requested to provide per farm information on farm management for 2019: (a) farm method (organic or nonorganic), (b) milking system [automatic milking system (AMS) or conventional], (c) presence of activity monitors or pedometers (yes or no), and (d) participation in veterinary herd health management programs (yes or no). Farms participating in a veterinary herd health management 
program are visited by their veterinarian based on a regular schedule for inspection of the animals, evaluating gathered data and providing advice (Brand et al., 1996).

\section{Measures and Data Handling}

This study focused exclusively on prostaglandin, $\mathrm{GnRH}$, and progesterone, as these are the most common reproductive hormone treatments in Dutch dairy herds that are prominently represented in international reproductive reviews (e.g., Thatcher et al., 2001; Rhodes et al., 2003; Gundling et al., 2012). To calculate the number of doses per quarter of a year, the total milliliters or number of devices sold by the veterinary practice was divided by the prescribed dose on the package leaflet (Appendix Table A1) and rounded off to a positive integer in MS Excel (Microsoft Corp.). The number of reproductive hormone doses in each quarter of the year was summed and defined as the annual number of reproductive hormone doses per farm per year. Assumptions were made regarding the dosage for one particular GnRH product, as this was given as a range on the package leaflet. The most common indication to prescribe GnRH is for the treatment of cystic ovarian disease, with a recommended dosage of 2 to $3 \mathrm{~mL}$. Subsequently, the prescribed dose for ovarian cysts, as mentioned in the herd treatment protocols of each clinic, was used for calculation of the total number of doses. The chosen dosages of progesterone and prostaglandin were based on the package leaflets, as there is only one recommended dosage for all indications.

To standardize for herd size, annual reproductive hormone use per farm was expressed as the number of reproductive hormone doses per 100 adult dairy cows per year in SPSS Statistics 25.0 (SPSS Inc.). The annual average number of adult dairy cows per farm was calculated by the average of the 4 quarters.

\section{Statistical Analyses}

First, descriptive statistics of the dairy herds and veterinary clinics included in the data set were determined. Thereafter, herd-level reproductive hormone use was quantified. Data were assumed to be count data, expressed as the annual number of reproductive hormone doses per 100 adult dairy cows. Exploration of the data set identified an excess of zeros, representing farms that did not apply reproductive hormones to their cows in a specific year or multiple years. Farms with reproductive hormone use (hereafter designated "users") were, therefore, analyzed separately from farms without any use (hereafter designated "nonusers"). Hence, the proportion of farms not using any reproductive hormones was determined, and reproductive hormone use was quantified only in herds that applied them.

Nonparametric tests were used to determine differences between study years regarding hormone use. Differences between years in the proportion of users were assessed by McNemar's test. Among users only, differences between study years regarding the magnitude of hormone use were assessed by the omnibus Friedman test. Post-hoc Wilcoxon signed-rank tests were subsequently performed to determine which paired years differed statistically. The same approach was used to determine yearly differences for each reproductive hormone and veterinary practices separately.

Regression models were developed to identify herd factors associated with reproductive hormone use in 2019. Given the excess of zeros in the data set, multiple probability distributions were evaluated. First, negative binomial distributions resulted in a better model fit than Poisson distributions based on the dispersion parameter $\alpha$. Subsequently, a standard negative binomial, a hurdle negative binomial, and a zero-inflated negative binomial distribution were evaluated for their model fit based on the Akaike information criterion, of which the latter resulted in the lowest value. A zero-inflated negative binomial distribution was, therefore, applied during the remaining regression modeling process. This distribution models 2 processes separately. The first part (hereafter named the "count part") concerns a negative binomial regression model with the number of hormone doses as the count variable in relation to the natural logarithm of the herd size as the offset. The second part of the model (hereafter named "the zero part") concerns a logistic regression model evaluating the excess of zeros (here, the nonusers). Because the count part of the model may also include zeros, herds without any hormone use can thus be included in both of the 2 parts of the model (whereas in the hurdle model all zeros are included in the zero part).

After determining the probability distribution, 6 potential herd-level factors were evaluated: farm method, milking system, presence of pedometers or activity monitors, participation in a veterinary herd health management program (all binary variables), herd size (a continuous variable that was categorized based on its quantiles), and veterinary clinic identification (categorical). Spearman rank correlation coefficients among all pairs of herd-level factors were calculated to avoid multicollinearity in the multivariable regression model. Because all Spearman rank correlation coefficients had a value $<0.5$, all 6 variables were added to both parts of the multivariable model. Thereafter, a backward selection procedure, based on the likelihood ratio test, was conducted on both parts of the model simultaneously until all factors were significantly contributing to the 
zero part, the count part, or both parts of the statistical model, or were considered a confounder. Confounding was assumed when coefficients changed more than $25 \%$ among nested models. Two-way interaction terms were not evaluated. Finally, model estimates were exponentiated to odds ratios for the zero part and incidence rate ratios for the count part.

Nonparametric tests were conducted using SPSS Statistics 25.0, and regression modeling was performed using Stata 15.1 (StataCorp). Statistical significance was set at $P<0.05$.

\section{RESULTS}

\section{Descriptive Statistics}

The median number of reproductive hormone doses per 100 adult dairy cows in farms that applied reproductive hormones is presented in Table 2 and shows an increase across all veterinary clinics between 2017 and 2019. The veterinary clinics varied regarding their use of reproductive hormones, as the median reproductive hormone use within farms that used reproductive hormones fluctuated over the years. Table 2 also gives insight into the use per reproductive hormone and shows that the median of prostaglandin use is the highest. Prostaglandins also accounted for the majority of doses (62.9\%), followed by $\mathrm{GnRH}(33.1 \%)$ and progesterone (4.0\%).

In the entire study period, $5.8 \%$ of the farms did not use any reproductive hormones, with the proportion of nonusers varying between 0.0 and $10.3 \%$ per clinic. No significant differences were determined between the years regarding the proportion of nonusers (Table 3 ). Fewer farms used progesterone in 2019 compared with

Table 2. Median reproductive hormone use within herds that used reproductive hormones per veterinary clinic and per reproductive hormone between 2017 and 2019

\begin{tabular}{lccc}
\hline & \multicolumn{3}{c}{$\begin{array}{c}\text { Median incidence rate of doses } \\
\text { per 100 adult dairy cows }\end{array}$} \\
\cline { 2 - 4 } Variable & 2017 & 2018 & 2019 \\
\hline Clinic & $35.1^{\mathrm{a}}$ & $38.4^{\mathrm{b}}$ & $43.4^{\mathrm{b}}$ \\
1 & $31.9^{\mathrm{a}}$ & $31.7^{\mathrm{a}}$ & $37.3^{\mathrm{a}}$ \\
2 & $35.2^{\mathrm{a}}$ & $42.8^{\mathrm{a}}$ & $40.6^{\mathrm{a}}$ \\
3 & $43.5^{\mathrm{a}}$ & $50.5^{\mathrm{ab}}$ & $46.3^{\mathrm{b}}$ \\
4 & $28.7^{\mathrm{a}}$ & $31.7^{\mathrm{b}}$ & $33.9^{\mathrm{b}}$ \\
5 & $32.1^{\mathrm{a}}$ & $37.1^{\mathrm{b}}$ & $39.0^{\mathrm{c}}$ \\
All & & & \\
Hormone & $11.4^{\mathrm{a}}$ & $13.0^{\mathrm{b}}$ & $13.2^{\mathrm{c}}$ \\
GnRH & $2.1^{\mathrm{a}}$ & $2.5^{\mathrm{b}}$ & $2.4^{\mathrm{b}}$ \\
Progesterone & $22.1^{\mathrm{a}}$ & $22.7^{\mathrm{a}}$ & $24.2^{\mathrm{a}}$ \\
Prostaglandin & &
\end{tabular}

\footnotetext{
${ }^{\mathrm{a}-\mathrm{c}}$ Median values in the same row with different superscripts are signifi-
} cantly different $(P<0.05)$.
Table 3. Proportion of farms (\%) not using reproductive hormones in 1 study year and in the consecutive period of 3 study years per veterinary clinic

\begin{tabular}{lrrrr}
\hline & \multicolumn{4}{c}{ Proportion of farms (\%) } \\
\cline { 2 - 5 } Clinic & 2017 & 2018 & 2019 & $2017-2019$ \\
\hline 1 & $15.6^{\mathrm{a}}$ & $12.3^{\mathrm{a}}$ & $13.6^{\mathrm{a}}$ & 5.2 \\
2 & $17.6^{\mathrm{a}}$ & $19.9^{\mathrm{a}}$ & $19.9^{\mathrm{a}}$ & 10.3 \\
3 & $3.3^{\mathrm{a}}$ & $3.3^{\mathrm{a}}$ & $4.4^{\mathrm{a}}$ & 0.0 \\
4 & $12.1^{\mathrm{a}}$ & $11.0^{\mathrm{a}}$ & $9.9^{\mathrm{a}}$ & 4.4 \\
5 & $13.5^{\mathrm{a}}$ & $16.0^{\mathrm{a}}$ & $14.2^{\mathrm{a}}$ & 6.3 \\
All & $13.3^{\mathrm{a}}$ & $13.8^{\mathrm{a}}$ & $13.4^{\mathrm{a}}$ & 5.8 \\
\hline
\end{tabular}

${ }^{a}$ Proportion values in the same row with different superscripts are significantly different $(P<0.05)$.

both previous years (Table 4). Also, $43.3 \%$ of all farms included throughout the study did not use any progesterone treatment in the entire study period, whereas a distinctly smaller proportion of farms did not use prostaglandin $(7.2 \%)$ or GnRH (12.5\%).

In 2019, the total number of reproductive hormone doses per 100 adult dairy cows ranged from 0 to 248 , with its distribution being right-skewed (Figure 1). The mean number of hormone doses per 100 adult dairy cows was 40.6, and its median was 32.8 (first quartile $=10.8$; third quartile $=59.3)$. Similar observations were made regarding the distribution of reproductive hormone use in 2017 and 2018.

\section{Herd-Level Factors}

The data set for the final regression model contained 719 farms, of which 625 used reproductive hormones (Table 5). A total of 41 farms were excluded from the regression model as a result of missing values on one or more herd-level factors. More than half of the number of farms $(55.8 \%)$ were participating in a veterinary herd health management program; pedometers or activity monitors were present on $27.7 \%$ of the farms; and, on $24.6 \%$ of the farms, cows were milked by an AMS. Only a small portion of the farms (6.4\%) were organic. Regarding combinations of technologies, $63 \%$ of the AMS herds had pedometers, in contrast with $16 \%$ in herds using a conventional milking system.

Table 4. Proportion of farms (\%) not using 1 specific reproductive hormone in 1 study year and in the consecutive period of 3 study years

\begin{tabular}{lcccc}
\hline & \multicolumn{4}{c}{ Proportion of farms (\%) } \\
\cline { 2 - 5 } Hormone & 2017 & 2018 & 2019 & $2017-2019$ \\
\hline GnRH & $25.5^{\mathrm{a}}$ & $23.7^{\mathrm{a}}$ & $22.8^{\mathrm{a}}$ & 12.5 \\
Progesterone & $65.9^{\mathrm{a}}$ & $62.5^{\mathrm{a}}$ & $58.7^{\mathrm{b}}$ & 43.3 \\
Prostaglandin & $17.9^{\mathrm{a}}$ & $18.0^{\mathrm{a}}$ & $18.3^{\mathrm{a}}$ & 7.2 \\
\hline
\end{tabular}

${ }^{\mathrm{a}, \mathrm{b}}$ Proportion values in the same row with different superscripts are significantly different $(P<0.05)$. 
Table 5. The number of farms per present herd-level factor in 2019 and their distribution among farms using reproductive hormones (users; $\mathrm{n}=625$ ) and those not using reproductive hormones (nonusers; $\mathrm{n}=94$ )

\begin{tabular}{lcccrc}
\hline Herd-level factor & Users & $\%$ & Nonusers & $\%$ & Total farms \\
\hline AMS $^{1}$ & 167 & 26.7 & 10 & 10.6 & 177 \\
Pedometers & 192 & 30.7 & 7 & 7.5 & 199 \\
Organic $^{2}$ & 20 & 3.2 & 7 & 7.5 & 27 \\
VHHM $^{2}$ & 391 & 62.6 & 10 & 10.6 & 401 \\
\hline
\end{tabular}

${ }^{1} \mathrm{AMS}=$ automatic milking system.

${ }^{2} \mathrm{VHHM}=$ veterinary herd health management program.

Table 6 shows the results of the final zero-inflated negative binomial regression model regarding the herdlevel factors associated with reproductive hormone use. Participating in a veterinary herd health management program contributed to both parts of the model. First, these herds had 0.1 (95\% CI: 0.0-0.2) greater odds of being nonusers (i.e., were thus more frequently a user), and, second, when they applied reproductive hormones, they used a higher number (incidence rate ratio $=1.5 ; 95 \%$ CI: $1.3-1.8$ ) than herds not participating in a veterinary herd health management program. Regarding the count part of the model, farms milking with an AMS used 1.2 (95\% CI: 1.1-1.4) times more reproductive hormones than farms with a conventional milking system after correcting for differences between veterinary clinics. Moreover, with an incidence rate ratio of 0.4 (95\% CI: $0.2-0.5$ ), organic farms used fewer hormones than nonorganic farms. Regarding the zero part of the model (i.e., the herds that did not apply any hormones), the smallest $50 \%$ of farms (<98 cows) had
2.7 (95\% CI: $1.2-6.4)$ to 3.0 (95\% CI: $1.3-6.6)$ times greater odds of being nonusers than farms in the largest herd size category. The presence of pedometers was associated with 0.39 (95\% CI: $0.2-1.0)$ times greater odds of being nonusers (i.e., these herds were thus more often a user).

\section{DISCUSSION}

To the best of our knowledge, this is the first study that describes an inventory of the use of reproductive hormones on a representative number of dairy farms in the Netherlands. A steady increase in use of reproductive hormones was shown from 2017 to 2019, with prostaglandins the most often used reproductive hormones, followed by GnRH and progesterone. The number of reproductive hormone doses per 100 adult dairy cows was higher on farms that participate in a herd health management program. We observed a similar effect on farms that used an AMS. In contrast, the presence of

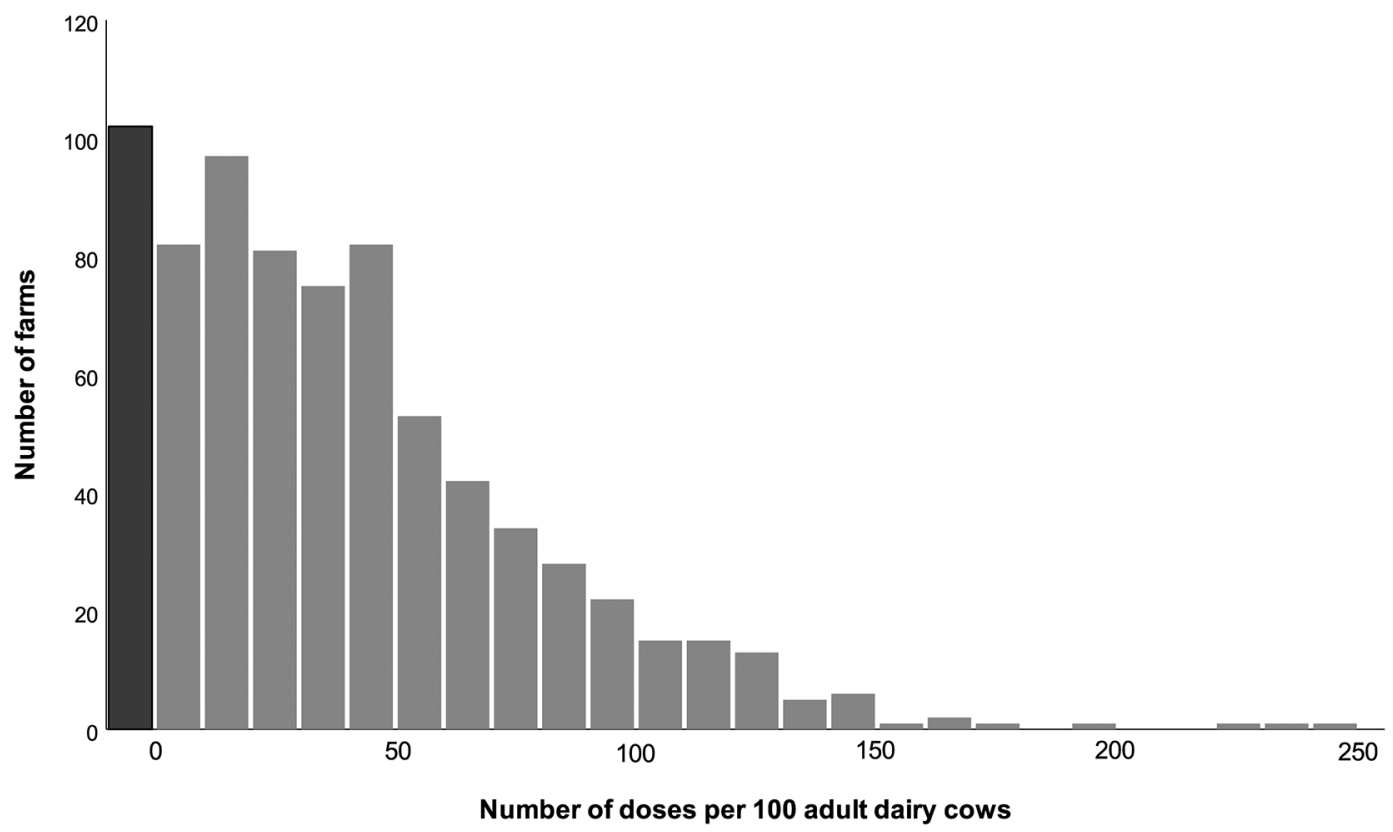

Figure 1. Frequency distribution of the number of reproductive hormone doses per 100 adult cows in representative Dutch farms using (gray) and not using (black) hormones in 2019. 
pedometers or activity tags on a farm was associated only with whether reproductive hormones were used or not, but not with the magnitude of use. Finally, organic farms used fewer hormone doses compared with conventional farms, which may be related to legislation and the restricted allowance of reproductive hormone use on organic farms. Use of reproductive hormones on Dutch organic farms is allowed only in a curative manner to treat fertility disorders, such as pyometra or cystic ovarian disease. Use of hormones in a noncurative manner, as in estrus induction, is not allowed in organic herds.

The results of this study show the magnitude of reproductive hormone use on Dutch dairy farms with a year-round calving pattern. Prostaglandins represent the major proportion of the reproductive hormone doses administered. Prostaglandins are successfully being used for the treatment of subestrus in individual cyclic cows to induce luteolysis (El-Shahat and Badr, 2011). Despite the wide discrepancy between studies that assessed the efficacy of treating metritis and endometritis early postpartum with prostaglandins (Haimerl et al., 2012, 2013; Borchardt et al., 2018), systemic administration of prostaglandins appears to be effective for chronic endometritis cases with a persistent corpus luteum (i.e., pyometra; Bicalho et al., 2016; Szenci, 2016).

Participation in a herd health management program had a major effect on the use of reproductive hormones and, therefore, shows the important role that veterinarians play in current hormone prescription. A possible reason for the greater use of reproductive hormones on these farms is the routine rectal examination of cows by a veterinarian (Brand et al., 1996; Derks et al., 2013), resulting in an early diagnosis of a fertility disorder or delayed estrus, followed by early treatment with reproductive hormones. The major objective of these herd health programs is to support the farm in reaching its targeted goals of farm economic performance (Noordhuizen and Wentink, 2001; De Kruif and Op-

Table 6. Herd-level factors associated with reproductive hormone use in 719 Dutch dairy herds in 2019 according to the final zero-inflated negative binomial regression model ${ }^{1}$

\begin{tabular}{|c|c|c|c|}
\hline Variable and category & Coefficient (SE) & $\operatorname{IRR}(95 \% \mathrm{CI})$ & $P$-value \\
\hline \multicolumn{4}{|l|}{ Count part ${ }^{2}$} \\
\hline Intercept & $-1.19(0.08)$ & & \\
\hline \multicolumn{4}{|l|}{ Milking system } \\
\hline Automatic & $0.18(0.07)$ & $1.20(1.05-1.37)$ & 0.01 \\
\hline Conventional & Referent & & \\
\hline \multicolumn{4}{|l|}{ Farm method } \\
\hline Organic & $-1.06(0.23)$ & $0.35(0.22-0.54)$ & $<0.0001$ \\
\hline \multirow{2}{*}{\multicolumn{4}{|c|}{ Participation in $\mathrm{VHHM}^{3}$}} \\
\hline & & & \\
\hline Yes & $0.43(0.07)$ & $1.53(1.34-1.75)$ & $<0.0001$ \\
\hline No & Referent & & \\
\hline \multicolumn{4}{|l|}{ Clinic ID } \\
\hline 1 & $0.07(0.08)$ & $1.07(0.91-1.26)$ & 0.39 \\
\hline 2 & $0.10(0.09)$ & $1.10(0.92-1.32)$ & 0.30 \\
\hline 3 & $0.34(0.11)$ & $1.40(1.14-1.73)$ & 0.001 \\
\hline 4 & $0.25(0.10)$ & $1.29(1.06-1.55)$ & 0.01 \\
\hline 5 & Referent & & \\
\hline Zero part ${ }^{4}$ & Coefficient (SE) & OR $(95 \% \mathrm{CI})$ & $P$-value \\
\hline Intercept & $-1.70(0.36)$ & & \\
\hline \multicolumn{4}{|l|}{ Pedometers } \\
\hline Yes & $-0.93(0.48)$ & $0.39(0.15-1.00)$ & 0.05 \\
\hline No & Referent & & \\
\hline \multicolumn{4}{|l|}{ Participation in VHHM } \\
\hline Yes & $-2.59(0.42)$ & $0.08(0.03-0.17)$ & $<0.0001$ \\
\hline No & Referent & & \\
\hline \multicolumn{4}{|l|}{ Herd size } \\
\hline$\leq 68$ & $1.09(0.41)$ & $2.96(1.33-6.60)$ & 0.01 \\
\hline $69-97$ & $1.00(0.43)$ & $2.73(1.17-6.37)$ & 0.02 \\
\hline $98-133$ & $0.28(0.48)$ & $1.32(0.51-3.37)$ & 0.57 \\
\hline$\geq 134$ & Referent & & \\
\hline
\end{tabular}


somer, 2004), which may result in greater reproductive hormone use. The current data set did not include the fertility performance of the herd, and, therefore, a relationship between reproductive hormone use and fertility indicators could not be made. Detailed farm-recorded data would be needed to estimate the contribution of other herd-level factors.

The current study showed that farms with an AMS had a higher level of reproductive hormone use than farms with a conventional milking system. As far as we are aware, no evidence has been documented that use of an AMS has a direct negative effect on reproductive performance, which could explain a higher need for reproductive hormones. We therefore believe that the effect of using an AMS occurs through other pathways. First of all, general management on AMS herds differs from farms that use a conventional milking system. For instance, Kruip et al. (2002) suggested that the number of days to first service may be prolonged in herds with an AMS due to the farmer's heat detection intensity. The presumed reduced presence of the farmer in the barn may negatively influence visual estrus detection. Less effective heat detection will result in a greater proportion of cows exceeding the voluntary waiting period and, therefore, a greater proportion of cows that will be treated to induce estrus.

Another difference between AMS herds and herds with a conventional milking system is the use of pedometers, which were more often present in AMS herds than in herds using a conventional milking system. It may therefore be that part of the effect on hormone use of having an AMS is through the presence of pedometers. Automatic estrus detection with pedometers has been shown to be more effective than visual estrus detection (Gaude et al., 2017) and also increases dairy farm profitability (Rutten et al., 2014; Pfeiffer et al., 2020). Therefore, we anticipated that pedometers would contribute to lower reproductive hormone use compared with visual estrus detection, but no such effect was observed in the current study. In fact, herds with pedometers more often belonged to the group of farms that used reproductive hormone treatments. It could also be that farms that invest in modern, labor-saving technologies, such as AMS and pedometers, are run by more progressive farmers. They may be more focused on economic objectives and likely have a more proactive management approach to achieve their desired high reproductive herd performance standards, which may result in a greater use of reproductive hormones. Several studies have shown significant associations between reproductive performance and herd health management (Lucy, 2007; Crowe et al., 2018).

Organic farms used far fewer reproductive hormones compared with nonorganic farms, but no evidence was found that organic farms were more represented in the group of nonusers. European Council Regulation No. 1804/1999 (European Council, 1999) allows organic farmers to treat an adult animal with an allopathic medicine only 3 times per year and, therefore, limits their use of reproductive hormones. Furthermore, the Dutch organization certifying organic farms (Skal) states that hormones are only permitted to be prescribed for curative purposes after a diagnosis and forbids the enhancement of reproductive performance with hormones.

Considering herd size, the magnitude of reproductive hormone use was not associated with different herd size classes. However, herds with an average of fewer than 98 cows were more often represented in the group of farms that did not use any reproductive hormone.

Potential biases may have caused over- or underestimation of reproductive hormone use. In our study, we assumed that all prescribed reproductive hormones were used according to the posology on the package leaflet and that the reproductive hormones were used in their entirety in the year of purchase. Because reproductive hormones are not over-the-counter medicines, every sales invoice equaled the same amount of available and used reproductive hormone on the farm. Furthermore, we have likely underestimated the number of $\mathrm{GnRH}$ doses, as all GnRH doses were based on the treatment of cystic ovarian disease. However, another indication to treat dairy cows with GnRH is delayed ovulation, administered between estrus and AI to stimulate ovulation (Dirandeh et al., 2009). The GnRH package leaflets prescribe half a dosage for this indication, compared with the dosage for cystic ovarian disease. The total number of GnRH doses may, therefore, be higher than currently estimated. Finally, the denominator to calculate the number of doses per 100 adult dairy cows was based on the average number of adult dairy cows in the herd. However, a limited number of reproductive hormones may have been used for estrus induction or reproductive disorders in young stock. The total number of doses per 100 adult dairy cows may, therefore, have been overestimated in a select number of herds. It should finally also be noted that identified associations in the risk factor analysis cannot be considered causal, given its cross-sectional study design.

It is important to realize that the number of reproductive hormone doses per 100 adult dairy cows is not equal to the actual number of treated animals on a farm. The estimated number of reproductive hormone doses per herd represents the maximum number of treated animals, on the assumption that each dose is given to a different animal. Some cows are likely to receive multiple doses of (different) hormones, as in Ovsynch protocols, which causes the number of treated 
animals to be lower than the number of reproductive doses per herd. We were not able to calculate the number of doses per individual cow, because only herd-level data were available.

To reach the maximum profitability of a dairy herd, farmers should find an optimum between reproductive performance, longevity of cows, and economic results. Commercial dairy farms are therefore challenged with making the most profitable management decisions among many options and implementing them correctly. However, the perception of consumers and citizens should not be underestimated and should, therefore, be included in management decisions. Consumers' interest in the care and housing of milking cows is increasing (von Keyserlingk et al., 2013), as is their interest in the quality and safety of dairy products (Drake, 2007). Ethical concerns keep arising among the public (Refsdal, 2000; Pieper et al., 2016), and acceptance of modern farming systems is, among other things, related to what the public finds important (Boogaard et al., 2011). Transparency in the process of milk production, including insight into key performance indicators and treatments, is effective in influencing social opinions about and acceptance of modern dairy farming (Beulens et al., 2005; Label Insight, 2016). We have made a first step by providing a transparent overview of reproductive hormone use on Dutch dairy farms and showing associations with some herd-level factors in an objective manner.

\section{CONCLUSIONS}

The present study provides an overview of reproductive hormone use and its association with herd-level factors on a representative number of Dutch dairy farms with a year-round calving pattern. Farm characteristics such as participation in a herd health management program and use of an AMS were associated with greater use of reproductive hormones, whereas organic farms used fewer reproductive hormones. The presence of pedometers did not influence the amount of reproductive hormones but was more often present on farms that used reproductive hormones. With this study, we have made a first step in achieving transparency in the Dutch dairy industry by providing an objective overview of reproductive hormone use on Dutch dairy farms and showing associations with some herd-level factors.

\section{ACKNOWLEDGMENTS}

We thank the veterinary clinics and veterinarians for their participation in this study. The authors declare that there is no conflict of interest.

\section{REFERENCES}

Beulens, A. J., D. F. Broens, P. Folstar, and G. J. Hofstede. 2005. Food safety and transparency in food chains and networks: Relationships and challenges. Food Control 16:481-486. https://doi .org/10.1016/j.foodcont.2003.10.010.

Bicalho, M. L. S., F. S. Lima, V. S. Machado, E. B. Meira Jr., E. K. Ganda, C. Foditsch, R. C. Bicalho, and R. O. Gilbert. 2016. Associations among Trueperella pyogenes, endometritis diagnosis, and pregnancy outcomes in dairy cows. Theriogenology 85:267-274 https://doi.org/10.1016/j.theriogenology.2015.09.043.

Boogaard, B. K., B. B. Bock, S. J. Oosting, J. S. Wiskerke, and A. J. van der Zijpp. 2011. Social acceptance of dairy farming: The ambivalence between the two faces of modernity. J. Agric. Environ. Ethics 24:259-282. https://doi.org/10.1007/s10806-010-9256-4.

Borchardt, S., S. Ludwig, and W. Heuwieser. 2018. Randomized clinical trial to evaluate the efficacy of prostaglandin $\mathrm{F}_{2 \alpha}$ to treat purulent vaginal discharge in lactating dairy cows. J. Dairy Sci. 101:11403-11412. https://doi.org/10.3168/jds.2018-14765.

Brand, A., J. P. T. M. Noordhuizen, and Y. H. Schukken. 1996. Principles of herd health and production management programs. Pages 3-14 in Herd Health and Production Management in Dairy Practice. Wageningen Pers.

Central Bureau for Statistics. 2020. Melkkoeien en melkgeiten per grootteklasse, 2000-2019 [Dairy cows and dairy goats by herd size, 2000-2019; dataset]. Accessed May 23, 2020. https://www .cbs.nl/nl-nl/maatwerk/2020/12/melkkoeien-en-melkgeiten-per -grootteklasse-2000-2019.

Crowe, M. A., M. Hostens, and G. Opsomer. 2018. Reproductive management in dairy cows-the future. Ir. Vet. J. 71:1. https://doi.org/ 10.1186/s13620-017-0112-y.

De Kruif, A., and G. Opsomer. 2004. Integrated dairy herd health management as the basis for prevention. Vlaams Diergeneeskd. Tijdschr. 73:44-52.

Denis-Robichaud, J., R. L. A. Cerri, A. Jones-Bitton, and S. J. LeBlanc. 2016. Survey of reproduction management on Canadian dairy farms. J. Dairy Sci. 99:9339-9351. https://doi.org/10.3168/jds .2016-11445.

Derks, M., T. van Werven, H. Hogeveen, and W. D. Kremer. 2013. Veterinary herd health management programs on dairy farms in the Netherlands: Use, execution, and relations to farmer characteristics. J. Dairy Sci. 96:1623-1637. https://doi.org/10.3168/jds .2012-6106.

Dirandeh, E., H. Kohram, and A. Shahneh. 2009. GnRH injection before artificial insemination (AI) alters follicle dynamics in Iranian Holstein cows. Afr. J. Biotechnol. 8:3672-3676.

Drake, M. A. 2007. Invited review: Sensory analysis of dairy foods. J. Dairy Sci. 90:4925-4937. https://doi.org/10.3168/jds.2007-0332.

El-Shahat, K. H., and A. Badr. 2011. Comparative study on efficacy of different medicaments on postpartum anestrus dairy cows. JABS 5:59-63.

European Council. 1999. Council Regulation (EC) No. 1804/1999. Supplementing Regulation (EEC) No 2092/91 on organic production of agricultural products and indications referring thereto on agricultural products and foodstuffs to include livestock production.

Gaude, I., A. Kempf, K. D. Strüve, and M. Hoedemaker. 2017. Comparison of visual and computerized estrous detection and evaluation of influencing factors. Anim. Reprod. Sci. 184:211-217. https: //doi.org/10.1016/j.anireprosci.2017.07.019.

Gundling, N., M. Feldmann, and M. Hoedemaker. 2012. Hormonal treatments for fertility disorders in cattle. Tierarztl. Prax. Ausg. G Grosstiere Nutztiere 40:255-263.

Haimerl, P., S. P. Arlt, and W. Heuwieser. 2012. Evidence-based medicine: Quality and comparability of clinical trials investigating the efficacy of prostaglandin $\mathrm{F}_{2 \alpha}$ for the treatment of bovine endometritis. J. Dairy Res. 79:287-296. https://doi.org/10.1017/ S002202991200012X

Haimerl, P., W. Heuwieser, and S. Arlt. 2013. Therapy of bovine endometritis with prostaglandin $\mathrm{F}_{2 \alpha}$ : A meta-analysis. J. Dairy Sci. 96:2973-2987. https://doi.org/10.3168/jds.2012-6154. 
Higgins, H. M., E. Ferguson, R. F. Smith, and M. J. Green. 2013. Using hormones to manage dairy cow fertility: The clinical and ethical beliefs of veterinary practitioners. PLoS One 8:e62993. https:/ /doi.org/10.1371/journal.pone.0062993.

KNMvD. 2013. De inzet van vruchtbaarheidshormonen in de rundveehouderij [The use of fertility hormones in cattle farming]. Accessed Feb. 17, 2021. https://www.knmvd.nl/app/uploads/ 2013/12/KNMvD-standpunt-vruchtbaarheidshormonen-in-de -rundveehouderij-1.pdf.

Kruip, T. A. M., H. Morice, M. Robert, and W. Ouweltjes. 2002. Robotic milking and its effect on fertility and cell counts. J. Dairy Sci. 85:2576-2581. https://doi.org/10.3168/jds.S0022-0302(02)74341 -5 .

Label Insight. 2016. How consumer demand for transparency is shaping the food industry. Accessed Jan. 27, 2021. https://www .labelinsight.com/hubfs/Label_Insight-Food-Revolution-Study .pdf.

Laven, R. 2019. Veterinary control of herd fertility in pastoral dairy herds. Pages 485-492 in Veterinary Reproduction and Obstetrics, 10th ed. W. B. Saunders.

Lucy, M. C. 2007. Fertility in high-producing dairy cows: Reasons for decline and corrective strategies for sustainable improvement. Soc. Reprod. Fertil. Suppl. 64:237-254. https://doi.org/10.5661/RDR -VI-237.

Lucy, M. C., S. McDougall, and D. P. Nation. 2004. The use of hormonal treatments to improve the reproductive performance of lactating dairy cows in feedlot or pasture-based management systems. Anim. Reprod. Sci. 82:495-512. https://doi.org/10.1016/j .anireprosci.2004.05.004.

McDougall, S., and C. W. R. Compton. 2006. Reproductive performance in the subsequent lactation of dairy cows previously treated for failure to be detected in oestrus. N. Z. Vet. J. 54:132-140. https://doi.org/10.1080/00480169.2006.36625.

Moore, S. G., and J. F. Hasler. 2017. A 100-Year Review: Reproductive technologies in dairy science. J. Dairy Sci. 100:10314-10331. https://doi.org/10.3168/jds.2017-13138.

Noordhuizen, J. P. T. M., and G. H. Wentink. 2001. Epidemiology: Developments in veterinary herd health programmes on dairy farms: A review. Vet. Q. 23:162-169. https://doi.org/10.1080/01652176 .2001 .9695106 .

Nowicki, A., W. Barański, A. Baryczka, and T. Janowski. 2017. OvSynch protocol and its modifications in the reproduction management of dairy cattle herds - An update. J. Vet. Res. 61:329336. https://doi.org/10.1515/jvetres-2017-0043.

Pfeiffer, J., M. Gandorfer, and J. F. Ettema. 2020. Evaluation of activity meters for estrus detection: A stochastic bioeconomic modeling approach. J. Dairy Sci. 103:492-506. https://doi.org/10.3168/jds .2019-17063.

Pieper, L., M. G. Doherr, and W. Heuwieser. 2016. Consumers' attitudes about milk quality and fertilization methods in dairy cows in Germany. J. Dairy Sci. 99:3162-3170. https://doi.org/10.3168/ jds.2015-10169.

Pugh, D. M. 2002. The EU precautionary bans of animal feed additive antibiotics. Toxicol. Lett. 128:35-44. https://doi.org/10.1016/ S0378-4274(01)00531-8.

Refsdal, A. O. 2000. To treat or not to treat: A proper use of hormones and antibiotics. Anim. Reprod. Sci. 60:109-119. https://doi.org/10 .1016/S0378-4320(00)00094-4.

Rhodes, F. M., S. McDougall, C. R. Burke, G. A. Verkerk, and K. L. Macmillan. 2003. Invited review: Treatment of cows with an extended postpartum anestrous interval. J. Dairy Sci. 86:1876-1894. https://doi.org/10.3168/jds.S0022-0302(03)73775-8.

Rutten, C. J., W. Steeneveld, C. Inchaisri, and H. Hogeveen. 2014. An ex ante analysis on the use of activity meters for automated estrus detection: To invest or not to invest? J. Dairy Sci. 97:6869-6887. https://doi.org/10.3168/jds.2014-7948.

Santos, V. G., P. D. Carvalho, C. Maia, B. Carneiro, A. Valenza, and P. M. Fricke. 2017. Fertility of lactating Holstein cows submitted to a Double-Ovsynch protocol and timed artificial insemination versus artificial insemination after synchronization of estrus at a similar day in milk range. J. Dairy Sci. 100:8507-8517. https://doi .org/10.3168/jds.2017-13210.

Schuster, J. C., H. W. Barkema, A. De Vries, D. F. Kelton, and K. Orsel. 2020. Invited review: Academic and applied approach to evaluating longevity in dairy cows. J. Dairy Sci. 103:11008-11024. https://doi.org/10.3168/jds.2020-19043.

Speksnijder, D. C., D. J. Mevius, C. J. M. Bruschke, and J. A. Wagenaar. 2015. Reduction of veterinary antimicrobial use in the Netherlands. The Dutch success model. Zoonoses Public Health 62:79-87. https://doi.org/10.1111/zph.12167.

Szenci, O. 2016. Recent possibilities for diagnosis and treatment of post parturient uterine diseases in dairy cow. J. Fertil. in Vitro 4:1000170. https://doi.org/10.4172/2375-4508.1000170.

Thatcher, W. W.. F. Moreira, J. E. P. Santos, R. C. Mattos, F. L. Lopes, S. M. Pancarci, and C. A. Risco. 2001. Effects of hormonal treatments on reproductive performance and embryo production. Theriogenology 55:75-89. https://doi.org/10.1016/S0093 $-691 \mathrm{X}(00) 00447-7$.

Van Calker, K. J., P. B. Berentsen, G. W. Giesen, and R. B. Huirne. 2005. Identifying and ranking attributes that determine sustainability in Dutch dairy farming. Agric. Human Values 22:53-63. https://doi.org/10.1007/s10460-004-7230-3.

von Keyserlingk, M. A. G., N. P. Martin, E. Kebreab, K. F. Knowlton, R. J. Grant, M. Stephenson, C. J. Sniffen, J. P. Harner III, A. D. Wright, and S. I. Smith. 2013. Invited review: Sustainability of the US dairy industry. J. Dairy Sci. 96:5405-5425. https://doi.org/10 $.3168 /$ jds.2012-6354.

\section{ORCIDS}

J. S. M. van der Laan (ํ) https://orcid.org/0000-0002-2954-4525

B. H. P. van den Borne 우 https://orcid.org/0000-0001-6248-4707

H. Aardema ๑ https://orcid.org/0000-0001-7318-5008

T. van Werven () https://orcid.org/0000-0003-2391-0253

\section{APPENDIX}

Table A1. Active constituents (per $\mathrm{mL}$ ) and their prescribed dosage from the package leaflet

\begin{tabular}{lll}
\hline $\begin{array}{l}\text { Active constituent } \\
\text { per mL }\end{array}$ & $\begin{array}{l}\text { Reproductive } \\
\text { hormone }\end{array}$ & $\begin{array}{l}\text { Prescribed } \\
\text { dosage }\end{array}$ \\
\hline $0.1 \mathrm{mg}$ of gonadorelin & GnRH & $5 \mathrm{~mL}$ \\
$50 \mu \mathrm{g}$ of gonadorelin & GnRH & $2 \mathrm{and} 3 \mathrm{~mL}^{1}$ \\
$0.004 \mathrm{mg}$ of buserelin & GnRH & $5 \mathrm{~mL}$ \\
1.38 g of progesterone & Progesterone & $1 \mathrm{device}$ \\
1.55 g of progesterone & Progesterone & 1 device \\
$5 \mathrm{mg}$ of dinoprost & Prostaglandin & $5 \mathrm{~mL}$ \\
$0.25 \mathrm{mg}$ of cloprestenol & Prostaglandin & $2 \mathrm{~mL}$ \\
$75 \mu \mathrm{g}$ of cloprestenol & Prostaglandin & $2 \mathrm{~mL}$ \\
$7.5 \mathrm{mg}$ of luprostiol & Prostaglandin & $2 \mathrm{~mL}$ \\
\hline
\end{tabular}

${ }_{3}^{1} 3 \mathrm{~mL}$ was used only by veterinary clinic 3 . 